\title{
Source parameters of the 2007 Noto Hanto earthquake sequence derived from strong motion records at temporary and permanent stations
}

\author{
Takahiro Maeda ${ }^{1}$, Masayoshi Ichiyanagi ${ }^{1}$, Hiroaki Takahashi ${ }^{1}$, Ryo Honda ${ }^{1}$, \\ Teruhiro Yamaguchi ${ }^{1}$, Minoru Kasahara ${ }^{1}$, and Tsutomu Sasatani ${ }^{2}$ \\ ${ }^{1}$ Institute of Seismology and Volcanology, Graduate School of Science, Hokkaido University, N10W8 Kita-ku, Sapporo 060-0810, Japan \\ ${ }^{2}$ Graduate School of Engineering, Hokkaido University, N13W8 Kita-ku, Sapporo 060-8628, Japan
}

(Received June 30, 2007; Revised December 6, 2007; Accepted January 8, 2008; Online published November 7, 2008)

\begin{abstract}
A large crustal earthquake, the 2007 Noto Hanto earthquake, occurred west off the Noto peninsula in Ishikawa prefecture, Japan, on March 25, 2007. We started temporary strong motion observation at five sites within the aftershock area from about $13 \mathrm{~h}$ after the main shock occurrence. We first applied the spectral inversion method to $S$-wave strong ground motion records at the temporary and permanent stations. We obtained source specta of the main shock and aftershocks, $Q_{s}$ (quality factor for $S$-wave) values $\left(Q_{s}=34.5 f^{0.95}\right)$ and site responses at 22 sites. We then estimated a source model of the main shock using the empirical Green's function method. The source model consists of three strong motion generation areas and well explains the observed records. Finally, we examined the consistency of the main-shock source models estimated from the above two analyses. The high-frequency level of the acceleration source spectrum based on the main-shock source model is consistent with the source spectrum estimated from the spectral inversion. The combined area of strong motion generation areas is approximately half of the value expected by the empirical relationship, and the high-frequency level of acceleration source spectrum is approximately 2.5 times larger than the empirical relationship for shallow inland and inter-plate earthquakes.
\end{abstract}

Key words: 2007 Noto Hanto earthquake, temporary strong motion observation, spectral inversion method, empirical Green's function method.

\section{Introduction}

A damaging large crustal earthquake, the 2007 Noto Hanto earthquake, occurred west off the Noto peninsula in Ishikawa prefecture at 0941 hours on March 25, 2007 (JST). The moment magnitude $\left(M_{\mathrm{W}}\right)$ determined by the Fnet Project of National Research Institute for Earth Science and Disaster Prevention (NIED) is 6.7. The focal depth and magnitude $\left(M_{\mathrm{J}}\right)$ determined by Japan Meteorological Agency (JMA) are $10.7 \mathrm{~km}$ and 6.9, respectively. A maximum seismic intensity of 6 upper in the JMA scale was observed at some stations around the epicenter. This earthquake caused widespread destruction: one person died, 359 persons were injured, and 15,757 houses were damaged as of June 14 (Fire and Disaster Management Agency, 2007).

We made an urgent strong motion observation at five sites within the aftershock area from 25 March to 14 May, 2007 (Fig. 1, Table 1). An accelerometer type strong motion seismograph (JEP-6A3, Mitsutoyo Co.) was installed at each observation site and seismic data were recorded continuously in a data logger (LS7000XT, Hakusan industry) at 100 sample/second.

In this paper, we estimate source parameters of the main shock and aftershocks, $Q_{s}$ values and site responses by applying the spectral inversion method to strong-motion

Copyright (c) The Society of Geomagnetism and Earth, Planetary and Space Sciences (SGEPSS); The Seismological Society of Japan; The Volcanological Society of Japan; The Geodetic Society of Japan; The Japanese Society for Planetary Sciences; TERRAPUB data at the temporary and permanent stations. We then estimate a main-shock source model using the empirical Green's function method. Finally, we examine the scaling of source parameters and the consistency of the main-shock source spectra deduced from the above two analyses.

2. Estimation of the Source, Path, and Site Effects Observed $S$-wave spectrum $O(f)$ is expressed as $O(f)=S(f) G(f) R^{-1} \exp \left(-\pi f T / Q_{s}(f)\right)$, where $R$ is the hypocentral distance, $R^{-1}$ represents a geometrical spreading, and $T$ is an $S$-wave travel time. We assume a geometrical spreading effect for the body wave, because the $S$ wave is dominant in analyzing time windows. Source spectra $S(f)$, path-averaged quality factor for $S$-wave $Q_{S}(f)$, and site responses $G(f)$ are estimated using strong ground motion records at the temporary and permanent stations. A spectral inversion method (Iwata and Irikura, 1988; Maeda and Sasatani, 2006) is adopted to the observed $S$-wave spectra from the main shock and small events. Two linear inequality constraints $\left(G(f) \geq 2\right.$ and $Q_{s}^{-1}(f) \geq 1000^{-1} f^{-1}$ ) are applied to the inversion. The former $(G(f) \geq 2)$ represents the free surface amplification effect and removes a trade-off problem between $S(f)$ and $G(f)$ (Iwata and Irikura, 1988).

$S$-wave Fourier amplitude spectra are calculated using Fast Fourier Transform. The time window for the analysis is $10.24 \mathrm{~s}$ for the main shock and $5.12 \mathrm{~s}$ for the small events; a cosine-shaped taper at $10 \%$ each end of the window is ap- 
Table 1 . The temporary observation stations.

\begin{tabular}{ccccl}
\hline Station & Latitude & Longitude & Observation period & Site condition* \\
\hline MNZ & 37.2922 & 136.7603 & $3 / 25,22: 45-5 / 14$ & Alluvial deposits \\
CHY & 37.2681 & 136.7361 & $3 / 25,23: 00-5 / 14$ & Miocene conglomerate \\
URK & 37.3083 & 136.7935 & $3 / 26,10: 10-5 / 14$ & Alluvial deposits \\
KOT & 37.2307 & 136.7102 & $3 / 26,16: 00-5 / 14$ & Miocene andesite lava \\
MTI & 37.3166 & 136.8996 & $3 / 27,11: 15-5 / 14$ & Miocene andesite lava \\
\hline
\end{tabular}

*Geological Survey Japan (1967).

(a)

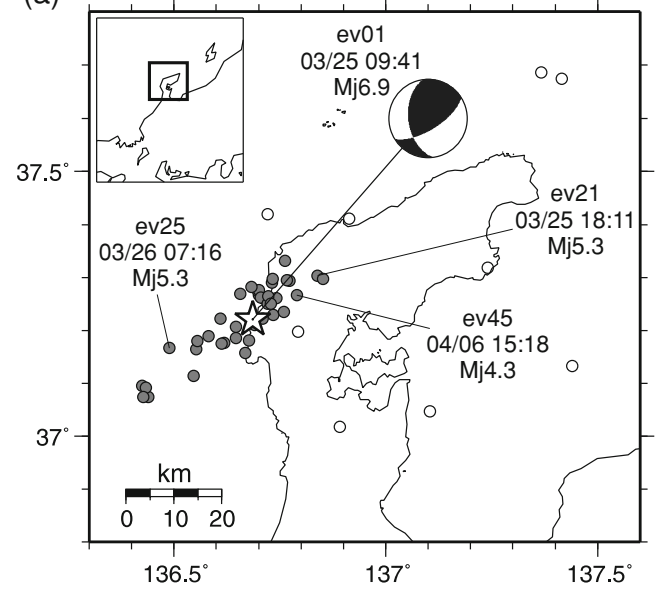

(b)

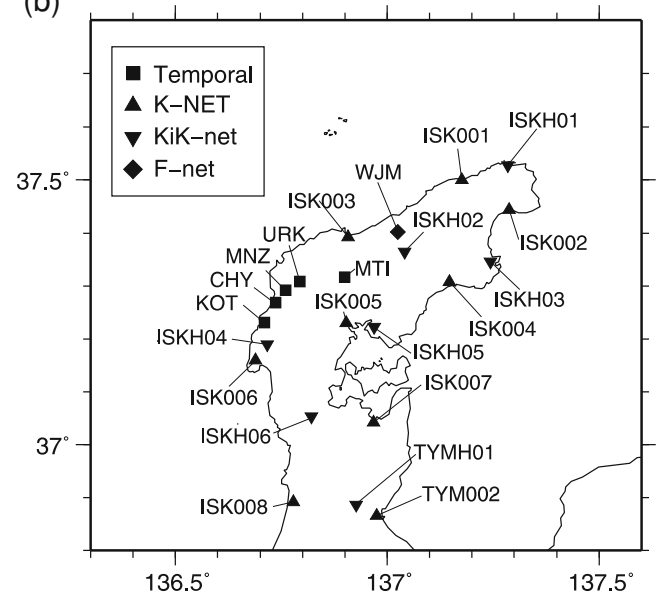

Fig. 1. Location map of epicenters and stations used in this study. (a) Star is epicenter of the 2007 Noto Hanto earthquake. Open circles are earthquakes used in the spectral inversion; solid circles are the aftershocks. Epicenters are taken from the JMA unified catalogue. The focal mechanism solution of the main shock determined by the F-net is shown. The study area is shown by a square in the inset map. (b) Solid symbols represent temporary and permanent strong-motion stations.

plied. To equalize a frequency interval, an extra $5.12 \mathrm{~s}$ with zero value is added to the small-event records. A moving average of $\pm 1 / 5 f_{0}$ window ( $f_{0}$, central frequency) is applied as a smoothing of amplitude spectra; the 25 central frequencies are chosen as they are distributed at a common interval from 0.1 to $20 \mathrm{~Hz}$ logarithmically. The vector summation of two horizontal component spectra is used for the inversion. Data with a signal-to-noise ratio greater than 2 at each frequency are used for the inversion; noise spectra are calculated using a seismogram just before the $S$-wave arrival. The frequency band to analyze is limited (about

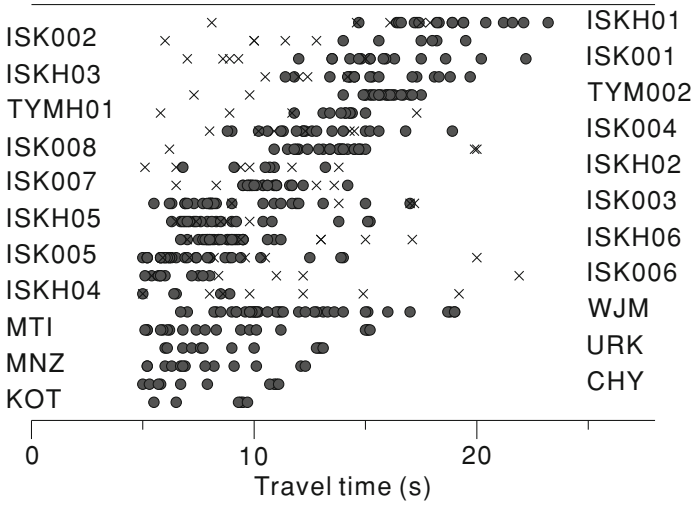

Fig. 2. The $S$-wave travel time distribution of data used in the spectral inversion. Circles are data from the main shock and aftershocks, and crosses are those from the additional events.

0.5-20 Hz) due to the low signal-to-noise ratio of the data.

We analyze $S$-wave spectra from the main shock and 37 aftershocks $\left(M_{\mathrm{J}}: 3.3-5.3\right.$, depth: $\left.0-13.5 \mathrm{~km}\right)$ at 22 stations in the Noto peninsula (Fig. 1) (dataset 1). The location, origin time, and magnitude of these events are taken from the JMA unified catalogue. The 22 stations consist of nine KNET, seven KiK-net, one F-net, and five temporary stations. We use data with peak horizontal amplitudes of less than $100 \mathrm{~cm} / \mathrm{s} / \mathrm{s}$ in order to avoid an influence of nonlinear site response. Although observed records of the main shock at the stations shown in Fig. 1 exceed $100 \mathrm{~cm} / \mathrm{s} / \mathrm{s}$, we use data at far-fault stations (ISK001, ISK002, ISK008, TYM002, ISKH01, ISKH02, WJM) for the inversion. Data having an $S$-wave travel time larger than $5 \mathrm{~s}$ are also used (Fig. 2).

Figure 3 shows the estimated $Q_{s}$ values, source spectra, and site responses (bold dotted lines). The site response at WJM equals 2 for most of frequencies and, therefore, WJM is a reference site of the inversion; this is a reasonable result, since WJM is placed in a vault. Theoretical site responses for the K-NET and KiK-net stations, where logging data are available, are shown in Fig. 3(c). Site response is evaluated using the Propagation Matrix method (Aki and Richards, 1980) for a vertical incident SH wave. A predominant frequency of the estimated site response with a steep spectral peak agrees with that of the theoretical site response (i.e. ISK005). In contrast, the amplitude of the estimated response is larger than that of the theoretical one; this is probably the effects of a deep structure from a basement, corresponding to a WJM site, to a logging-data depth; the logging-data depths are up to about $20 \mathrm{~m}$ and $200 \mathrm{~m}$ for the K-NET and KiK-net, respectively.

Estimated site responses show a systematic feature in that 
$(\mathrm{a})_{10^{3}}$

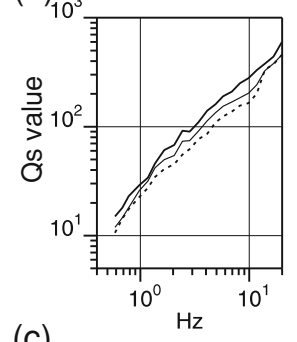

(c)
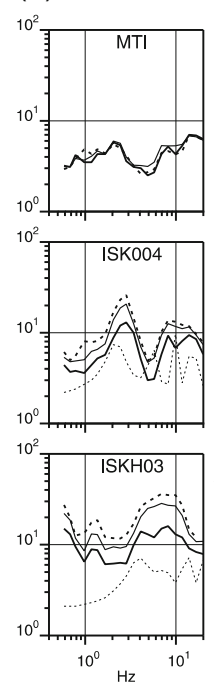

(b)
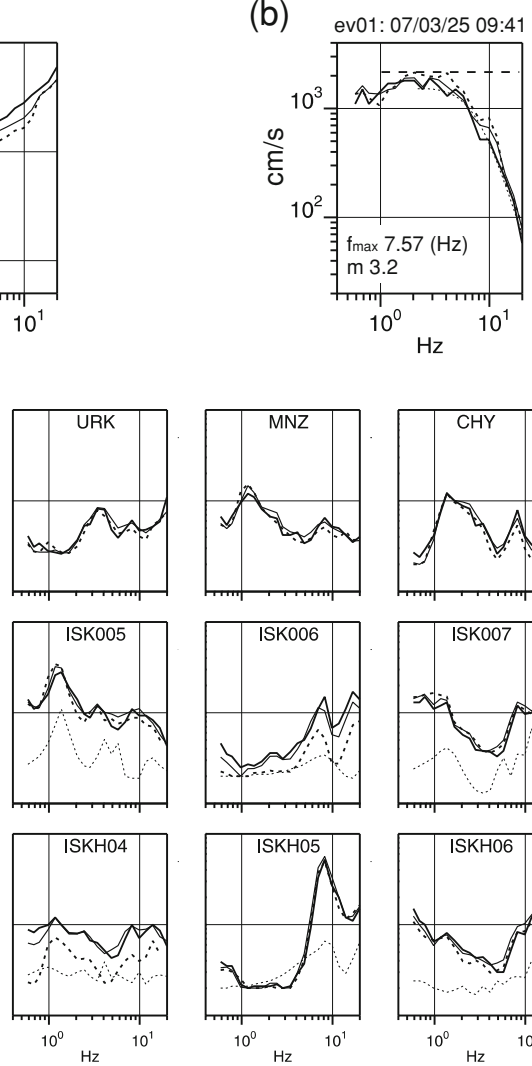
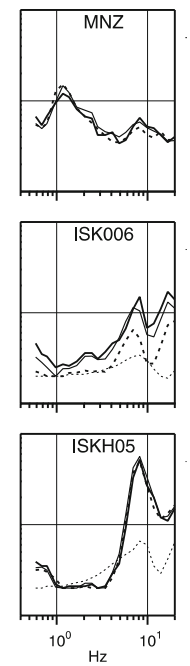
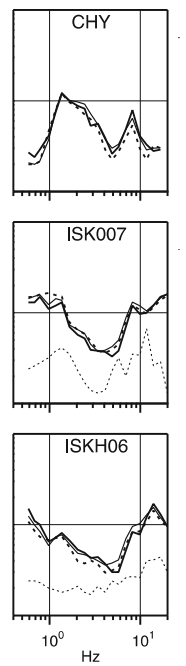
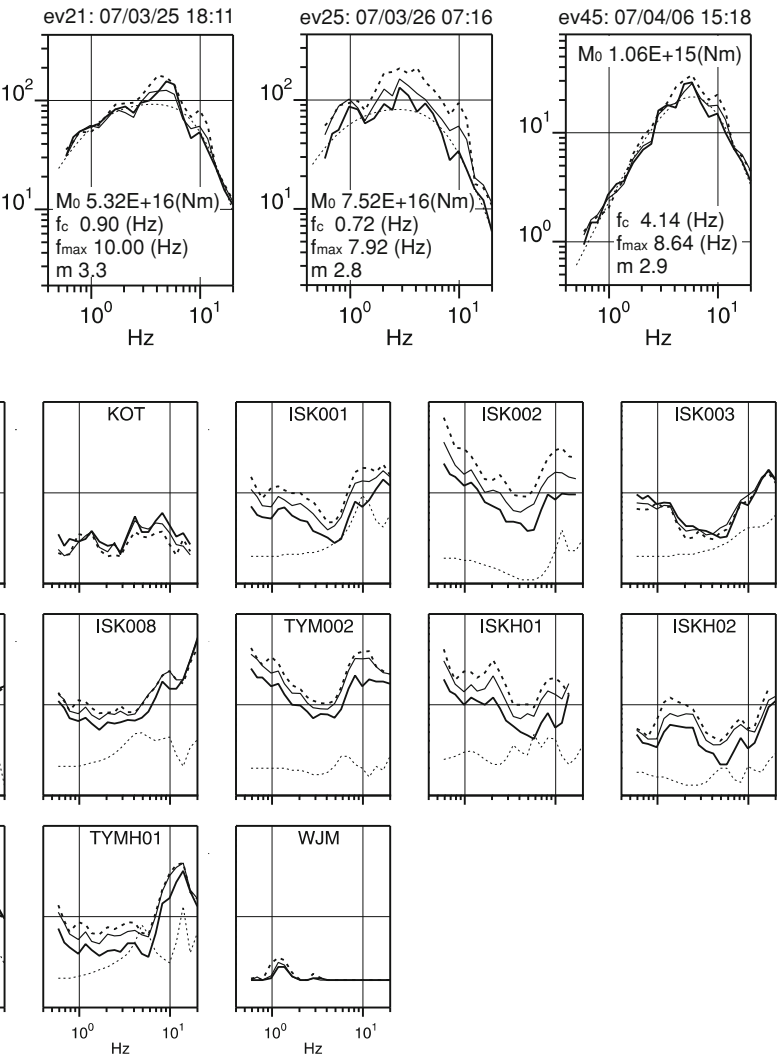

Fig. 3. Results of the spectral inversion. (a) $Q_{s}$ values, (b) acceleration source spectra for selected events, and (c) inverted site responses. Bold, thin and dotted lines are the results from inversion of the data subsets (dataset 3), all available data (dataset 2), and data on the main shock and aftershocks (dataset 1), respectively. Theoretical source spectra and site responses are shown by a thin dotted line. The high-frequency level of the main-shock acceleration source spectrum (ev01) based on fault parameters of the strong motion generation areas (Fig. 5) is shown as a broken line.

stations farther from the aftershock area have a larger amplification. This distance dependency may arise from a specific configuration of stations and earthquakes; the aftershock area is small compared with the extent of stations (Fig. 1). In this case, observed data at each station have approximately the same hypocentral distance and travel time (Fig. 2) and, therefore, a reliability in the estimate of the $Q_{s}$ value and site response may decrease. To maintain a wide travel-time range for each station, nine events occurring around the Noto peninsula are added to the data set (open circles in Fig. 1(a); $M_{\mathrm{J}}$ : 3.7-4.8, depth: 6.7-19.3 km). This new data set (dataset 2) provides a wide travel-time range for the permanent stations (Fig. 2). We also make data subsets to decrease the contribution of the aftershocks to the inversion results as follows.

The 47 events (total) are divided into two groups; Group A includes the main shock and nine events occurring outside of the aftershock area, and Group B includes 37 aftershocks. The inversion analysis is performed using 100 data subsets (dataset 3). Each data subset includes 20 events: ten events from Group A and another ten events randomly selected from Group B. The final result (Fig. 3; bold lines) is an average of the 100 inversion results; source spectra from Group B are averages of 19-38 models, depending on a random selection. Standard deviations of the results are very small and, therefore, not shown in the figure.

$Q_{s}$ values estimated from dataset 3 are larger than those from the dataset 1 . The site responses at the near aftershock area (i.e. ISK006) increase using dataset 3, while those far from the aftershock area (i.e. ISK001) decrease. On the other hand, the source spectra are stable and independent of the data sets. These facts indicate that the trade-off problem between $Q_{s}(f)$ and $G(f)$ is reduced using the data subsets.

We fit a power law to the frequency dependence of $Q_{s}$ values for the frequency band $1-10 \mathrm{~Hz}$ and obtain $Q_{s}=$ $34.5 f^{0.95}$. In the same region, Kato and Ikeura (2007) obtained $Q_{s}=30 f^{1.2}$ using the spectral inversion method. These reserchers used strong ground motion data from the main shock and aftershocks and gave a constraint condition on source spectra. Our $Q_{s}$ values estimated from the main shock and aftershocks (dataset 1) are expressed as $Q_{s}=$ $25.6 f^{0.86}$. A part of the discrepancy may result from the different constraint conditions.

Figure 3(b) shows a part of the estimated source spectra together with the theoretical ones. The theoretical displacement spectra $M(f)$ based on the $\omega^{-2}$ model are represented as

$$
M(f)=M_{0} \frac{1}{1+\left(f / f_{c}\right)^{2}} \frac{1}{1+\left(f / f_{\max }\right)^{m}},
$$

where $M_{0}$ is a seismic moment, $f_{c}$ is a corner frequency, and $f_{\max }$ is a high-frequency cutoff of the source spectrum. We adapt the method of Andrews (1986) for a finite frequency band $(0.5-5 \mathrm{~Hz})$ to determine $f_{c}$ and flat level of source displacement spectrum $\Omega_{0}$ from the inverted source spectra. Seismic moment is calculated from $\Omega_{0}$; $M_{0}=4 \pi \rho_{s} \beta_{s}{ }^{3} R_{0} \Omega_{0} / R_{\theta \phi} \sqrt{\rho_{g} \beta_{g} / \rho_{s} \beta_{s}}$, where $\rho$ and $\beta$ are 
(a)

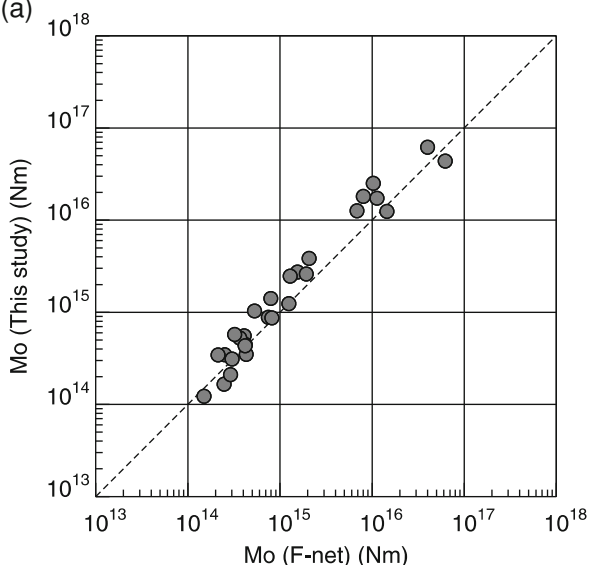

(b)

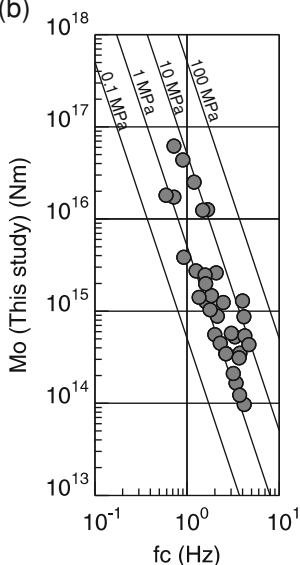

(c) $10^{18}$

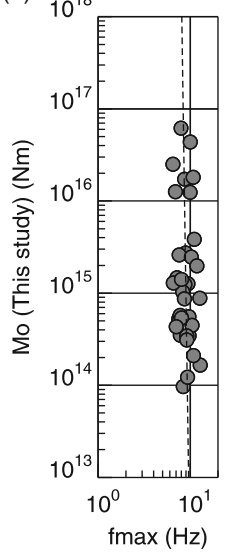

Fig. 4. (a) Relation between the seismic moment $\left(M_{0}\right)$ determined in this study and that determined by F-net, (b) $M_{0}-f_{c}$ (corner frequency) relation, and (c) $M_{0}-f_{\max }$ (high-frequency cutoff) relation. Lines of constant stress drop (Brune, 1970, 1971) are shown in (b); $S$-wave velocity of $3.5 \mathrm{~km} / \mathrm{s}$ is assumed. Regression line is shown in (c).

density and $S$-wave velocity, respectively; subscripts of $g$ and $s$ indicate the value at the site and source, respectively; we assume $\rho_{s}=2.7 \mathrm{~g} / \mathrm{cm}^{3}, \rho_{g}=2.3 \mathrm{~g} / \mathrm{cm}^{3}, \beta_{s}=3.5 \mathrm{~km} / \mathrm{s}$, and $\beta_{g}=1.5 \mathrm{~km} / \mathrm{s}$. $R_{\theta \phi}$, a radiation pattern coefficient at a source, is 0.63 (Boore and Boatwright, 1984), and $R_{0}=1 \mathrm{~km}$ is assumed. We then estimate $f_{\max }$ and the power of decay $m$ through a grid search to minimize the residual between the inverted and theoretical source spectra. The search range for $f_{\max }$ is $f_{c}$ to $20 \mathrm{~Hz}$ at intervals of $0.01 \mathrm{~Hz}$, and that for $m$ is 0 to 5 at intervals of $0.1 . f_{c}$ and $M_{0}$ for the main shock are not estimated because $f_{c}$ of the main shock is not included in the frequency band analyzed. Estimated seismic moments are 1.4 times larger than those by the F-net project on average (Fig. 4(a)). Figure 4(b) shows that these events are roughly governed by the scaling relation that $M_{0}$ is proportional to $f_{c}^{-3}$. In Fig. 4(c), $f_{\max }$ shows weak dependence on $M_{0}$, and $f_{\max }=14.8 M_{0}^{-0.015}$ (the logarithmic mean over these events is $8.9 \mathrm{~Hz}$ ).

\section{Estimation of the Main-shock Source Model}

Using the empirical Green's function (EGF) method (Irikura, 1986; Irikura et al., 1997; Kamae and Irikura, 1998), we construct a source model of the main shock that explains observed broad-band strong ground motions. The
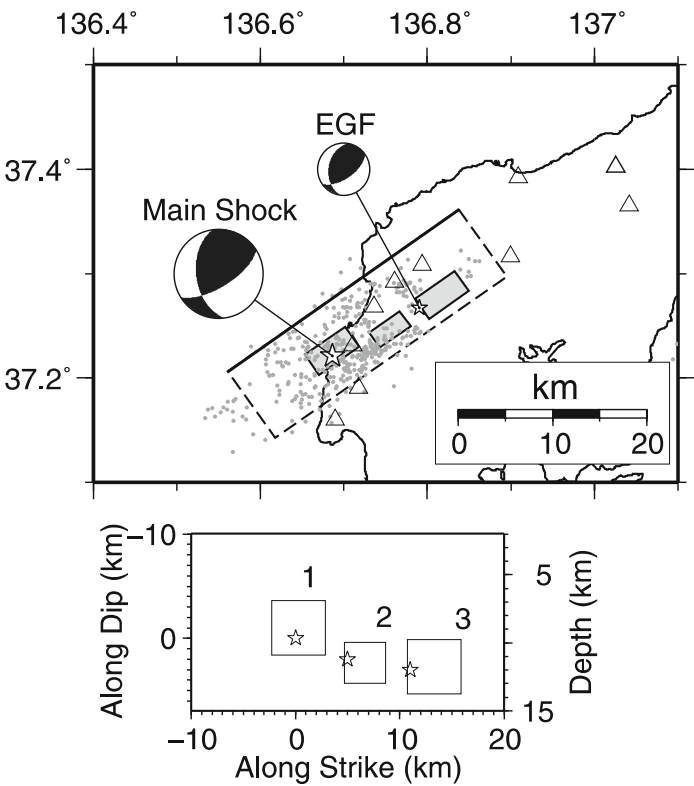

Fig. 5. Source model of the 2007 Noto Hanto earthquake estimated using the EGF method. (Upper) Triangles are strong-motion stations. Open and gray rectangles are the assumed fault plane and estimated SMGAs, respectively. Open stars are the epicenter of the main shock and the elemental aftershock used in the modeling, respectively. Focal mechanisms after F-net are also shown. Gray dots are aftershocks occurring on 25 March, 2007. (Lower) Source model. Stars represent the start points of rupture.

EGF method synthesizes waveforms from a target earthquake (main shock) using those from an elemental small earthquake (aftershock) occurring close to the target earthquake as Green's functions. We assume that strong motions are generated from several strong motion generation areas (SMGA) placed on the main-shock fault plane; SMGA usually coincides with the asperity area (Miyake et al., 2003). The waveform synthesization is based on a rupture propagation: the rupture starts from a point on each SMGA with a time delay and radially propagates at an average rupture speed with random time shift (Irikura, 1986).

We assume that the source model consists of three SMGAs, since three $S$-wave pulses are seen in N-S component velocity at WJM (Fig. 6). The geometry of the fault plane is assumed by referring to the aftershock distribution and focal mechanism solution: (strike, dip) $=\left(55^{\circ}\right.$, $60^{\circ}$ ) (Fig. 5). The position and area of SMGAs, stress drop ratio between SMGAs and an elemental event, rise time of SMGAs, and average rupture speed are estimated through the forward modeling of acceleration, velocity, displacement waveforms, and spectra at six stations shown in Fig. 6. In particular, we model the three $S$-wave velocity pulses at WJM and ISK001, and the first $S$-wave velocity pulse at ISK008 and TYM002 (Fig. 6). The area of SMGA is evaluated as multiples of the elemental-event area and the dimension ratio between SMGA and elemental event; the elemental-event area is estimated by searching in the neighborhood of the value based on the Brune $(1970,1971)$ model and $f_{c}$ of the source spectrum (Fig. 3(b), ev45). For calculating a travel time from SMGA to each station, we made an $S$-wave travel-time curve for each station using the observed travel-time data instead of assuming uniform 
Table 2. Source parameters of the main shock and aftershock used in EGF modeling.

\begin{tabular}{ccccccccc}
\hline Event & Origin time & Epicenter & $\begin{array}{c}\text { Depth } \\
(\mathrm{km})\end{array}$ & $M_{\mathrm{J}}$ & $\begin{array}{c}M_{0} \\
(\mathrm{~N} \mathrm{~m})\end{array}$ & $\begin{array}{c}\text { Area } \\
(\mathrm{km})\end{array}$ & $\begin{array}{c}\text { Stress drop } \\
(\mathrm{MPa})\end{array}$ \\
\hline Target & $07 / 03 / 2509: 41$ & $37.221 \mathrm{~N}, 136.686 \mathrm{E}$ & 10.7 & 6.9 & $1.36 \times 10^{19 *}$ & - & - & \\
Element & $07 / 04 / 0615: 18$ & $37.267 \mathrm{~N}, 136.790 \mathrm{E}$ & 11.7 & 4.3 & $1.06 \times 10^{15 \dagger}$ & 0.4225 & $9.38^{\ddagger}$ \\
\hline
\end{tabular}

*F-net. ${ }^{\dagger}$ This study; Fig. 3. ${ }^{\ddagger}$ Brune $(1970,1971)$.

Table 3. Parameters for strong motion generation areas (SMGAs).

\begin{tabular}{ccccccccc}
\hline No & $\begin{array}{c}M_{0} \\
(\mathrm{~N} \mathrm{~m})\end{array}$ & $N^{*}$ & $C^{*}$ & $\begin{array}{c}\text { Area } \\
\left(\mathrm{km}^{2}\right)\end{array}$ & $\begin{array}{c}\text { Stress drop } \\
(\mathrm{MPa})\end{array}$ & $\begin{array}{c}\text { Rise time } \\
(\mathrm{s})\end{array}$ & $\begin{array}{c}\text { Rupture time } \\
(\mathrm{s})\end{array}$ & $\begin{array}{c}\text { Slip }^{\dagger} \\
(\mathrm{m})\end{array}$ \\
\hline 1 & $2.71 \times 10^{18}$ & 8 & 5 & 27.0 & 46.9 & 0.9 & 0.0 & 3.03 \\
2 & $1.14 \times 10^{18}$ & 6 & 5 & 15.2 & 46.9 & 0.9 & 2.9 & 2.0 \\
3 & $2.17 \times 10^{18}$ & 8 & 4 & 27.0 & 37.5 & 0.9 & 4.4 & 2.43 \\
\hline Total & $6.02 \times 10^{18}$ & & & 69.3 & & \\
\hline
\end{tabular}

${ }^{*} N$ and $C$ are the ratio of the dimension and stress drop between SMGA and elemental event, respectively. ${ }^{\dagger} \mu=33$ GPa.
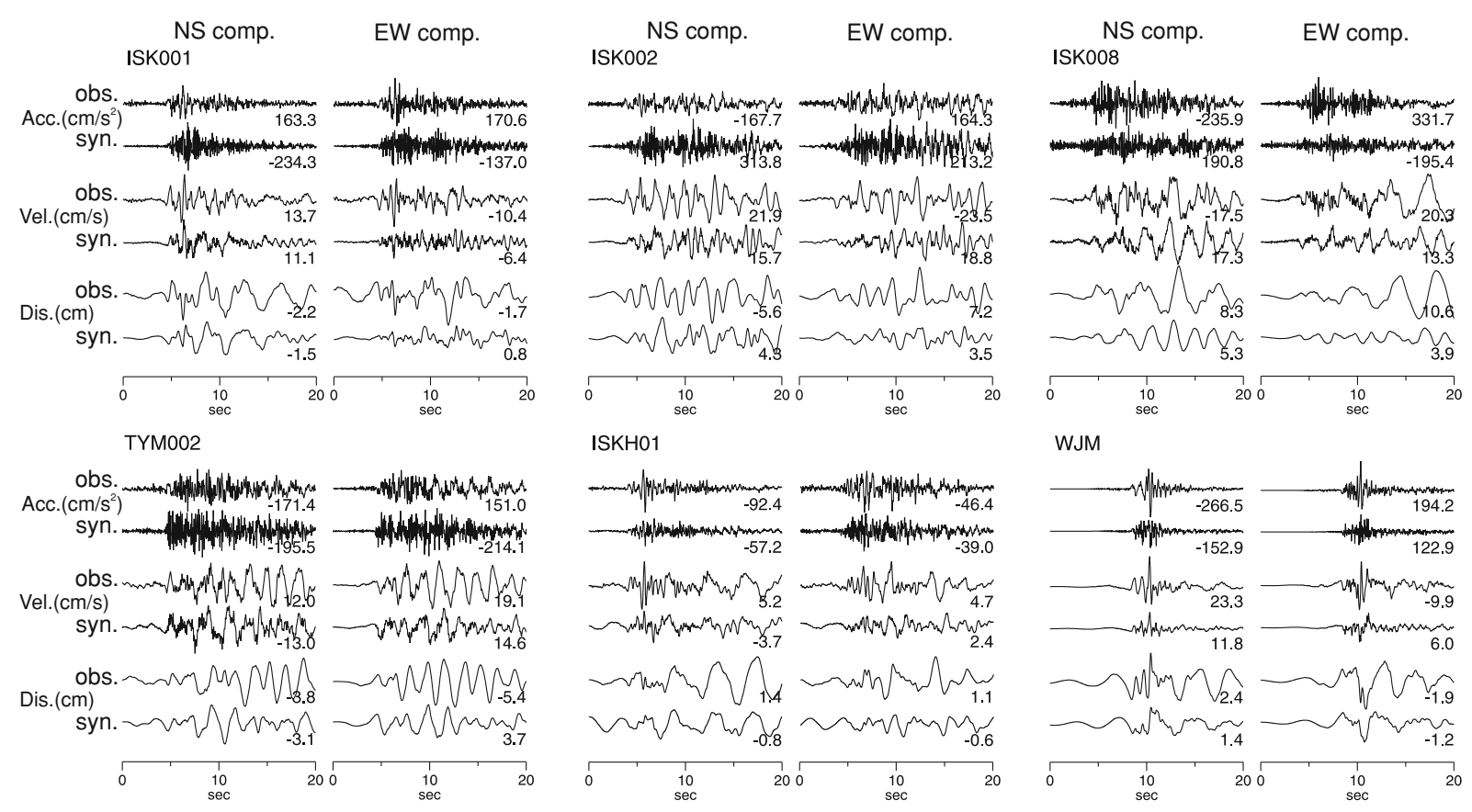

Fig. 6. Comparisons of observed waveforms with synthetic ones calculated using the source model (Fig. 5) for NS and EW components. Each row shows acceleration (top), velocity (middle), and displacement (bottom) waveforms. The numbers on the lower right show a peak amplitude.

$S$-wave speed. Following Kamae et al. (1990), different effects of attenuation $\left(Q_{s}\right)$ and $f_{\max }$ between the main shock and elemental event are corrected using the results of spectral inversion (Fig. 3(a), (b); ev01 and ev45).

We compare the observed and synthetic data at one KiKnet, one F-net, and four K-NET stations for the frequency band of $0.3-10 \mathrm{~Hz}$; bore-hole records (at about $200 \mathrm{~m}$ depth) are used for the KiK-net station. The aftershock $\left(M_{\mathrm{J}} 4.3\right)$ occurring at 1518 hours on 6 April is used as an elemental event, since this aftershock has a focal mechanism similar to that of the main shock (Fig. 5) and shows simple $S$-wave waveform at the stations used in the modeling. The source parameters for the main shock and elemental aftershock are shown in Table 2.

After many trials, we obtain the source model and parameters for SMGAs, as shown in Fig. 5 and Table 3. The rupture speed is estimated to be $2.8 \mathrm{~km} / \mathrm{s}$. The observed and synthetic waveforms show a satisfactory agreement both in shape and amplitude (Fig. 6). The three velocity pulses observed at WJM are reproduced in the synthetic waveforms, but amplitudes are underestimated. This may be due to the fact that WJM locates on near the nodal direction of the elemental event, and we do not make a correction of a radiation pattern.

\section{Discussion}

The main-shock source model (Fig. 5) consists of three SMGAs; one is around hypocenter and the others are at a deeper part of the fault plane beneath the land region. Slip distribution inferred from InSAR data (Geographical Survey Institute, 2007; Disaster Prevention Research Institute, Kyoto University and NIED, 2007) shows a large slip around the hypocenter and no or a very small shallow slip beneath the land region; these features are consistent with 
our model. The slip distribution based on the InSAR data shows, by contrast, a large shallow slip beneath sea region that is not recognized by our data set.

The combined area of SMGA is approximately the half of the value expected by the empirical relationship between the combined area of asperities and seismic moment reported by Somerville et al. (1999). This discrepancy may be due to the dispersion of the empirical relationship; the value of combined area of SMGA is within the spread in values of combined asperity areas used in determining the empirical relationship. However, alternatively, this may be due to the underestimate of the shallow slip beneath the sea region that is not estimated in this study.

Following Dan et al. (2002), we calculate the highfrequency level of acceleration source spectrum $A$ using the areas and stress drops of SMGA. The $A$ value based on an asperity model (Das and Kostrov, 1986) is expressed as $A=4 \pi \beta_{s}{ }^{2} \sqrt{\Sigma\left(r_{n} \Delta \sigma_{n}\right)^{2}}$, where $r_{n}$ and $\Delta \sigma_{n}$ are the equivalent radius and stress drop of the $n$-th SMGA, respectively. Substituting the parameters in Table 3 into this equation, we obtain $A=3.19 \times 10^{19}\left(\mathrm{~N} \mathrm{~m} / \mathrm{s}^{2}\right)$. After dividing the $A$ value by $\left(4 \pi \rho_{s} \beta_{s}{ }^{3} R_{0}\right)$, we compare the value with the inverted source spectrum (Fig. 3; ev01). The high-frequency levels derived from the two analyses are consistent. Hence, the source model corresponds to the asperity model. However, this $A$ value is approximately 2.5 times larger than the empirical relationship for shallow inland and inter-plate earthquakes obtained by Dan et al. (2001). Kato and Ikeura (2007) also estimated the $A$ value from the inverted source spectrum; their $A$ value is approximately twofold larger than the empirical relationship. These facts indicate that the Noto Hanto earthquake strongly excited high-frequency seismic waves from deep SMGAs.

\section{Conclusions}

We applied the spectral inversion method to the $S$-wave strong motion data from the 2007 Noto Hanto earthquake sequence recorded at temporary and permanent stations in the Noto peninsula. The source spectra of the events show that these events are roughly governed by the scaling relation; $M_{0}$ is proportional to $f_{c}^{-3}$. We pointed out that a trade-off problem between $Q_{s}$ values and site responses may occur in the case that the extent of hypocenters is much smaller than that of stations in the spectral inversion. We constructed the main-shock source model using the empirical Green's function method. In this model, a combined area of strong motion generation areas was approximately half of the value expected by the empirical relationship. The high-frequency levels of acceleration source spectra $A$ based on this source model and the spectral inversion were consistent; this indicates that the source model corresponded to the asperity model. The $A$ value was approximately 2.5 times larger than the empirical relationship, indicating strong excitation of high-frequency seismic waves during the Noto Hanto earthquake.

Acknowledgments. We would like to express our sincere gratitude to the local government and schools in the Noto peninsula; they kindly allowed us to make observation in their area. We thank the National Research Institute for Earth Science and Disaster Prevention for providing strong-motion data of K-NET, KiK-net, Fnet, and moment tensor solutions of F-net, and the Japan Meteorological Agency for providing hypocentral information and focal mechanisms. This manuscript was greatly improved by constructive comments by two anonymous reviewers. Some of the figures in this paper were made using GMT (Wessel and Smith, 1995).

\section{References}

Aki, K. and P. G. Richards, Quantitative Seismology. vol. 1, 557 pp, W. H. Freeman and Company, 1980.

Andrews, D. J., Objective determination of source parameters and similarity of earthquakes of different size, in Earthquake Source Mechanics, Maurice Ewing Series 6, edited by S. Das, J. Boatwright, and C. H. Scholz, 259-267, Am. Geophys. Union, Washington, D.C., 1986.

Boore, D. M. and J. Boatwright, Average body-wave radiation coefficient, Bull. Seismol. Soc. Am., 74, 1615-1621, 1984.

Brune, N., Tectonic stress and the spectra of seismic shear waves from earthquakes, J. Geophys. Res., 75, 4997-5009, 1970.

Brune, N., Correction, J. Geophys. Res., 76, 5002, 1971.

Dan, K., M. Watanabe, T. Sato, and T. Ishii, Short-period source spectra inferred from variable-slip rupture models and modeling of earthquake faults for strong motion prediction by semi-empirical method, J. Struct. Contr. Eng. AIJ, 545, 51-62, 2001 (in Japanese with English abstract).

Dan, K., T. Sato, and K. Irikura, Characterizing source model for strong motion prediction based on asperity model, in Proc. 11th Japan Earthquake Engineering Symposium, 555-560, 2002 (in Japanese with English abstract).

Das, S. and B. V. Kostrov, Fracture of single asperity on a finite fault, in Earthquake Source Mechanics, Maurice Ewing Series, Vol. 6, American Geophys. Union, 91-96, 1986.

Disaster Prevention Research Institute, Kyoto University and $\mathrm{Na}$ tional Research Institute for Earth Science and Disaster Prevention, http://cais.gsi.go.jp/YOCHIREN/JIS/173/image173/018.pdf, 2007.

Fire and Disaster Management Agency, http://www.fdma.go.jp/data/ 010705141514086149.pdf, 2007.

Geographical Survey Institute, http://cais.gsi.go.jp/YOCHIREN/JIS/173/ image 173/016-017.pdf, 2007.

Geographical Survey Japan, Geological Map of Japan 1:200,000 Nanao and Toyama, 1967.

Irikura, K., Prediction of strong acceleration motions using empirical Green's function, Proc. 7th Japan Earthq. Eng. Symp., 151-156, 1986.

Irikura, K., T. Kagawa, and H. Sekiguchi, Revision of the empirical Green's function method by Irikura (1986) (program and abstracts), Seism. Soc. Japan 2, B25, 1997 (in Japanese).

Iwata, T. and K. Irikura, Source parameters of the 1983 Japan Sea earthquake sequence, J. Phys. Earth., 36, 155-184, 1988.

Kamae, K. and K. Irikura, Source model of the 1995 Hyogo-ken Nanbu earthquake and simulation of near-source ground motion, Bull. Seismol. Soc. Am., 88, 400-412, 1998.

Kamae, K., K. Irikura, and Y. Fukuchi, Prediction of strong ground motion for $M 7$ earthquake using regional scaling relations of source parameters, J. Struct. Constr. Eng, AIJ, 416, 57-70, 1990 (in Japanese with English abstract).

Kato, K. and T. Ikeura, Source, path, and site effects of the Noto Hanto Earthquake in 2007; Preliminary results based on K-NET and KiK-net records, Japan Geoscience Union Joint Meet., Z255-P036, 2007.

Maeda, T. and T. Sasatani, Two-layer $Q_{s}$ structure of the slab near the southern Kurile trench, Earth Planets Space, 58, 543-553, 2006.

Miyake, H., T. Iwata, and K. Irikura, Source characterization for broadband ground-motion simulation: kinematic heterogeneous source model and strong motion generation area, Bull. Seismol. Soc. Am., 93, 2531-2545, 2003.

Somerville, P., K. Irikura, R. Graves, S. Sawada, D. Wald, N. Abrahamson, Y. Iwasaki, T. Kagawa, N. Smith, and A. Kowada, Characterizing crustal earthquake slip models for the prediction of strong ground motion, Seismol. Res. Lett., 70, 59-80, 1999.

Wessel, P. and W. H. Smith, New version of the Generic Mapping Tools released, EOS Trans. AGU, 329, 1995.

T. Maeda (e-mail: tmaeda@mail.sci.hokudai.ac.jp), M. Ichiyanagi, H. Takahashi, R. Honda, T. Yamaguchi, M. Kasahara, and T. Sasatani 